\title{
A Value Stream Approach For Greening The IT Department
}

Mohammad Dadashzadeh, Ph.D, Oakland University, USA T.J. Wharton, Ph.D., Oakland University, USA

\begin{abstract}
In this paper, we consider the application of Green Value Stream Mapping for greening the information technology functional area of organizations. We advocate the use of Information Technology Infrastructure Library (ITIL®) processes to consider value stream maps for both the manufacturing side of the IT department as well as its service delivery arm. In addition, we present steps to be taken by the IT department to eliminate waste in each of seven green waste areas and consider the impact of new technologies for greening the IT department.
\end{abstract}

Keywords: Sustainability; ITIL; Green Computing; Green IT; Value Stream Map; Green Value Stream Mapping

\section{INTRODUCTION}

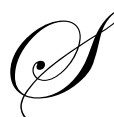

ince the publication of the Brundtland Report (1987) and the introduction of the term "sustainable development" as "development that meets the needs of the present without compromising the ability of future generations to meet their own needs," sustainability has transitioned from a fad to fashion to a business imperative. As pointed out by Esty and Winston (2006), there are two interlocking forces behind the Green Wave: limits to natural world resources and increasing stakeholders' concerns about the environment. These forces have combined to move sustainability from the environmentalists' agenda, to an item on the corporate social responsibility checklist, to the priority list of the CEO. Organizations can no longer ignore these concerns. To survive requires the development of new business models and strategies that can capitalize on the new opportunities and innovations resulting through the creation of value for stakeholders and for society (Lazlo, 2008).

The range of "green" environmental issues facing an organization is quite varied. It is certainly different for a manufacturing concern than a service organization. Even within the same industry, and similar value chains, the particular issues and opportunities can be different.

Although it is possible to list generic steps to follow for the greening of the organization, crafting a corporate sustainability strategy demands a more systematic approach. And, like other examples of strategic initiatives to create competitive advantage, successful implementation brings about gains in efficiency and effectiveness that directly translate to bottom line success in terms of reduced costs and increased revenues. It is, therefore, not surprising that the focus on sustainability has triggered research in methodologies for greening the organization.

In this paper, we consider the application of the green value stream mapping (GVSM) (Wills, 2009) for greening the information technology functional area (IT) of an organization. We argue that greening the IT functions is an integral part of an organizational strategy of sustainability. Within an organization, the IT department is a manufacturing concern in that it designs and develops software, as well as a service function that supports users by delivering a multitude of services ranging from help desk troubleshooting to training to delivering access to information resources. We consider green value stream maps for both the manufacturing side of the IT department and its service delivery arm and consider variations for in-house as well as outsourced IT organizations. In addition, we present steps to be taken by the IT department to eliminate waste in each of seven green waste areas and consider the impact of new technologies for greening the IT department. 


\section{GREEN VALUE STREAM APPROACH TO SUSTAINABILITY}

Sustainability is perhaps best defined in terms of the four objectives proposed by Natural Step, a non-profit organization formed in 1989 with the vision of creating a sustainable society. Building on the findings of the Brundtland Report (1987) they concluded that to create a sustainable society we must:

- $\quad$ Eliminate our contribution to the progressive buildup of substances extracted from the Earth's crust,

- $\quad$ Eliminate our contribution to the progressive buildup of chemicals and compounds produced by society,

- $\quad$ Eliminate our contribution to the progressive physical degradation and destruction of nature and natural processes, and

- Eliminate our contribution to conditions that undermine people's capacity to meet their basic human needs (Natural Step, 2011).

Three of these principles relate to how we treat the environment; the fourth relates to basic needs of people. Natural Step argues that in a business these objectives form the basis of making strategic decisions that are in the best interest of shareholders and society.

Many businesses have been slow in adopting or even considering such sustainability policies, believing that they would hurt profits. In reality, companies that green their supply chains and optimize operations in alignment with a strategic plan with a focus on sustainability, not only help the environment, but typically improve their bottom line by lowering costs and minimizing waste and often enhance their competitive position by creating new opportunities in the market place. Sustainable business practices are not only compatible with, but supportive of, strategic competitive advantage (Orsato, 2006; Rusinko, 2007). Additionally, failure to be proactive to the changing regulatory and political environment related to sustainability can leave many organizations at a distinct competitive disadvantage, if not shuttered.

The IT department can be a major catalyst in this process. Greening the IT department and its services is an important step in moving toward organizational sustainability. The process of Greening IT involves strategic and tactical decisions that relate to:

- Reducing the 'carbon footprint' of the organization's computing operation,

- $\quad$ Using the services of IT to help reduce the organization's overall carbon footprint,

- Incentivizing and supporting greener behavior by the organization's employees, customers and suppliers, and

- $\quad$ Ensuring the sustainability of the resources used by IT (Hird, 2008).

Arguably, most gains can be made in reducing the carbon footprint created by the organization and the IT function. Methodologies and tools for greening IT should primarily focus on these areas. Green Value Stream Mapping (GVSM) approach provides such an option.

Sustainability and green thinking are complementary to an organization's lean philosophy and lean initiatives. Given the similarity of goals, it is difficult to separate them. Lean, as a process improvement philosophy adopted by many organizations, focuses on the systematic identification and removal of waste while improving value to the customer in a production or service process. By adopting lean practices an organization seeks to deliver high quality products and services to its customers in the most effective manner possible. This is achieved by developing an organizational strategy that is based on the continual pursuit of waste reduction, with waste being defined as any activity that does not add value to the product or service. Within a lean system seven categories of wastes are generally targeted for reduction:

- $\quad$ Overproduction: produce more product or service than is needed or before it is actually required,

- Waiting: delay which occurs whenever time is not being used efficiently,

- Transportation: unnecessary movement between processes, 
- $\quad$ Over-processing: a subtle form of waste related to doing more than what the customer requires;

also, any form of inspection,

- Inventories: unnecessary raw material, work in process (WIP) and stored final product; usually, a direct result of other causes of wastes,

- Motion: typically related to ergonomics and unnecessary motions such as bending, stooping, stretching, reaching, or extra steps, and

- $\quad$ Defects or Rework: resulting from poor quality, training and management.

Value Stream Mapping (VSM) is a useful lean tool to assist in the process of identifying and reducing these wastes. Taking a process view from the customer's perspective, a value stream map defines the various activities and relationships within the value stream of an organization as they exist (current-state map) and compares them to an ideal state - one with little or no waste (ideal-state map).

Figure 1 shows a generic template of a current-state value stream map for the production of a gear. When completed the map would provide a depiction of the stream of activities over time, and the information necessary to produce the gear. Elements of the value stream would include information such as current-process steps, information flow, inventory flow, material movement, and detailed order and process information such as takt times, lead times, lot sizes, average queue times, set up times, utilization, and scrap rates. To identify areas of improvement this map would be compared to an ideal-state map which shows the process under perfect conditions, where all steps are value-added. In the context of the two maps, waste would include any activity that does not add value as perceived by the customer, or any activities that impede movement toward the ideal state.

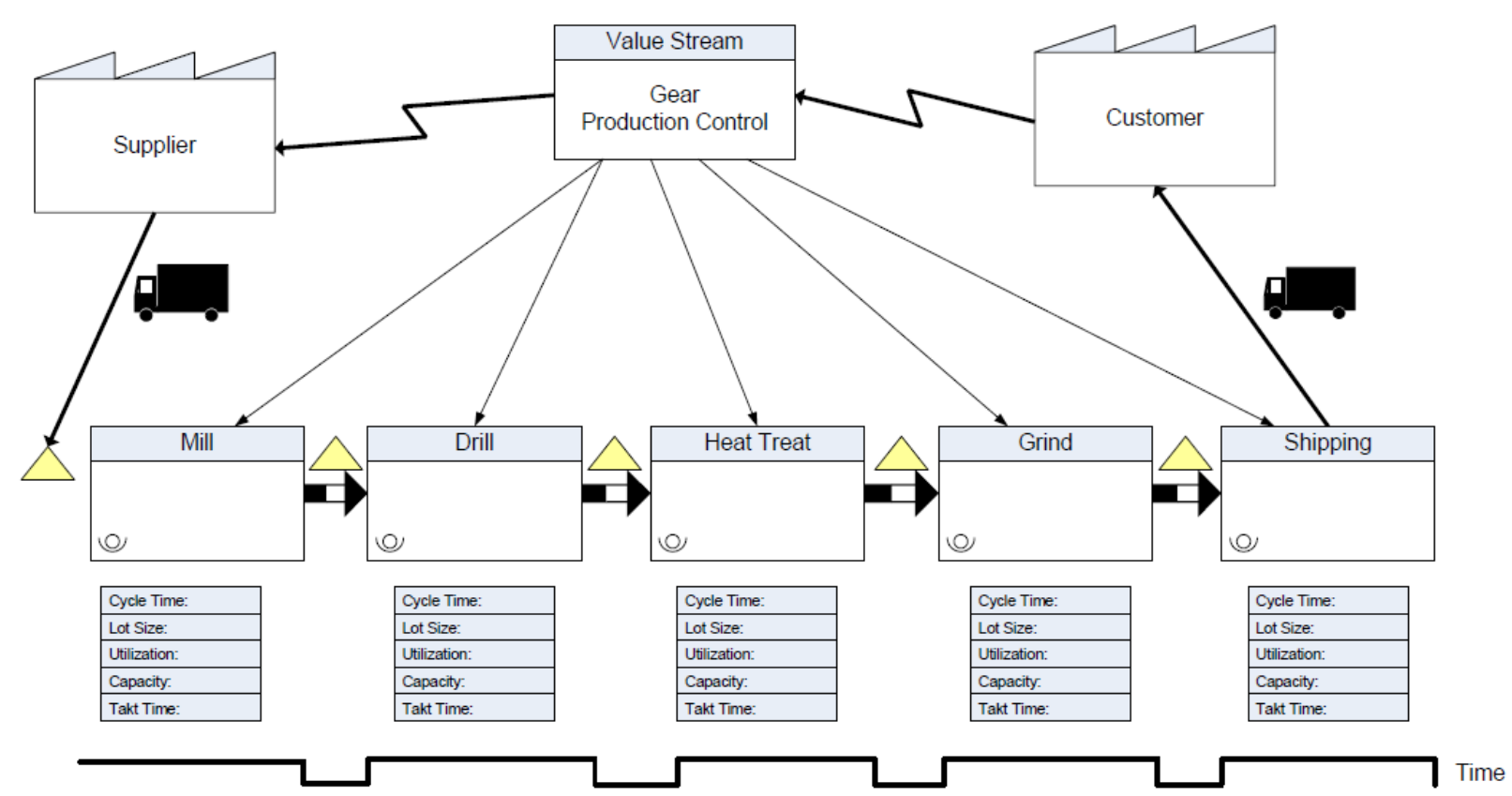

Figure 1. Template Current-State Value Stream Map for Gear Production.

The goal in lean process improvement and waste reduction is to continually move the current-state map towards the ideal-state map, updating the current-state map as you make improvements. To measure movement toward the ideal state a box score is maintained of the critical process metrics which are related to the process information collected. The current-state box score metrics are continually updated for comparison to the ideal-state metrics. Rother and Shook (1999), and Nash and Poling (2008) provide detailed descriptions of the development and use of value stream maps for waste reduction. 
In his book, Green Intentions, Wills (2009) proposes an approach similar to VSM for use in greening the enterprise. Specifically, the proposed Green Value Stream Mapping (GVSM) methodology systematically considers all activities in the value stream or operation of the business and determines if, from the perspective of the environment (as opposed to the customer in the context of lean VSM), each activity, process, operation, or thing is positive, good, or valuable. If not, it is considered wasteful and must be transformed or eliminated. The goal is to move an organization toward sustainability by focusing on the reduction of "green wastes" that impact the environment. The seven green wastes considered in this approach are defined in Table 1.

Table 1. Green Wastes. Adapted from Green Intentions (Wills, 2009)

\begin{tabular}{|l|l|l|}
\hline \multicolumn{2}{|c|}{ Waste } & \multicolumn{1}{|c|}{ Definition of Waste } \\
\hline & Energy & $\begin{array}{l}\text { Costs associated with consuming more energy than required from a source } \\
\text { that negatively impacts the environment }\end{array}$ \\
\hline & Materials & $\begin{array}{l}\text { Costs related to using more water than needed and costs to have it taken } \\
\text { away and cleaned }\end{array}$ \\
\hline & Garbage & $\begin{array}{l}\text { Using materials that are designed into products that end up in the landfill } \\
\text { rather than reused }\end{array}$ \\
\hline & Transportation & $\begin{array}{l}\text { Paying for something that has a negative impact on the environment if you } \\
\text { throw it away, than paying again to dispose of it }\end{array}$ \\
\hline & Biodiversity & $\begin{array}{l}\text { Costs due to excess and unnecessary travel } \\
\text { that results in negative impacts on the environment from the burning of } \\
\text { fossil fuels }\end{array}$ \\
\hline
\end{tabular}

Wills (2009) proposes a seven step process in Green Value Stream Mapping:

1. Gain management support, develop a vision, and appoint green champions within the organization,

2. Shift your thinking; grasp the concept of looking at things from the perspective of the environment,

3. Be able to list each of the seven green wastes and the step-by-step process for eliminating them,

4. Create a current-state green stream map by identifying and measuring the seven green wastes in your value stream,

5. Create a future-state green stream map by following the minimization step for each of the green wastes. Then, implement the solutions on your future-state map continuously until you have minimized all wastes as much as possible,

6. Pursue the perfection of total elimination of all seven wastes by following the final steps in the elimination of each of the green wastes, thus allowing you to achieve your green state, and

7. Carry GVSM to your supply chain.

These steps are similar to the overall process recommended for lean VSM, thus providing a natural extension of VSM. Beginning with a current-state green value stream map, the goal is to identify and measure the green wastes so that specific actions and programs can be implemented to eliminate them leading to reduced costs, and increased societal benefits. 


\section{IT DEPARTMENT'S GREEN VALUE STREAMS}

The first step in developing an IT department's current-state green value stream map is to map the value streams found in the IT department. But, what are the value streams of the IT department? An IT department has both a manufacturing side in that it designs, develops and delivers a product - an IT application - to the end-users, as well as a service side in the important sense that it supports end-users in the course of the lifecycle of the delivered product. For example, developing a website for a marketing campaign entails a flow of activities that are different than the flow of activities needed to replace a malfunctioning desktop computer with a new one. Therefore, because of the variety of products and services offered by an IT department, each of which may go through different processes and need different administration and support, one appears to be faced with the daunting task of mapping a myriad of value streams.

It was precisely the recognition of the multitude of technologies, products, and services that often preoccupy an IT department at the expense of focusing on client needs that led to the publication of a catalog of best practices for the IT organization, which has come to be known as ITIL. With the release of its third version, ITIL v3 has rapidly become the de facto best practice standard in IT service management and the lens through which the value of IT services is viewed and measured. Indeed, the ITIL philosophy has found its way into a number of other reference models including Microsoft Operations Framework, IBM's IT Process Model, HP's IT Service Management (ITSM) Reference Model, and ISO 20000. Organizations seeking to become certified against ISO 20000 standard must fulfill certain mandatory requirements that promote the "adoption of an integrated process approach to effectively deliver managed services to meet the business and customer requirements." Although, there is no formal relationship between ISO 20000 and ITIL, the first version of the ISO 20000 standard, published in 2005, was designed to be aligned with ITIL version 2. ITIL v3, in turn, was published in 2007 to achieve even better alignment with ISO 20000 (IT Process Maps, 2011). Therefore, to be proactive, it seems reasonable that any attempt at mapping the value streams of an IT department should consider the best practices recommended by ITIL.

ITIL v3 is organized as five core publications that form the ITIL v3 Service Lifecycle which collectively address best practices for managing services from their creation to retirement. Each of the core publications is focused on a specific stage of the lifecycle:

- $\quad$ Service Strategy - Determining which types of service (e.g., data visualization, remote desktop, a timecard application on Android, etc.) should be offered and to which business end-users/customers,

- $\quad$ Service Design - Identifying service requirements and devising new service offerings as well as changes and improvements to existing ones,

- $\quad$ Service Transition - Building or acquiring and deploying new or modified services,

- $\quad$ Service Operation - Carrying out operational tasks including supporting end-users in the course of using the service, and

- $\quad$ Continual Service Improvement - Learning from past successes and failures and continually improving the effectiveness and efficiency of services and processes.

Figure 2 depicts each of the five stages of the ITIL v3 Service Lifecycle along with the "specialized organizational capabilities" needed for each stage. 


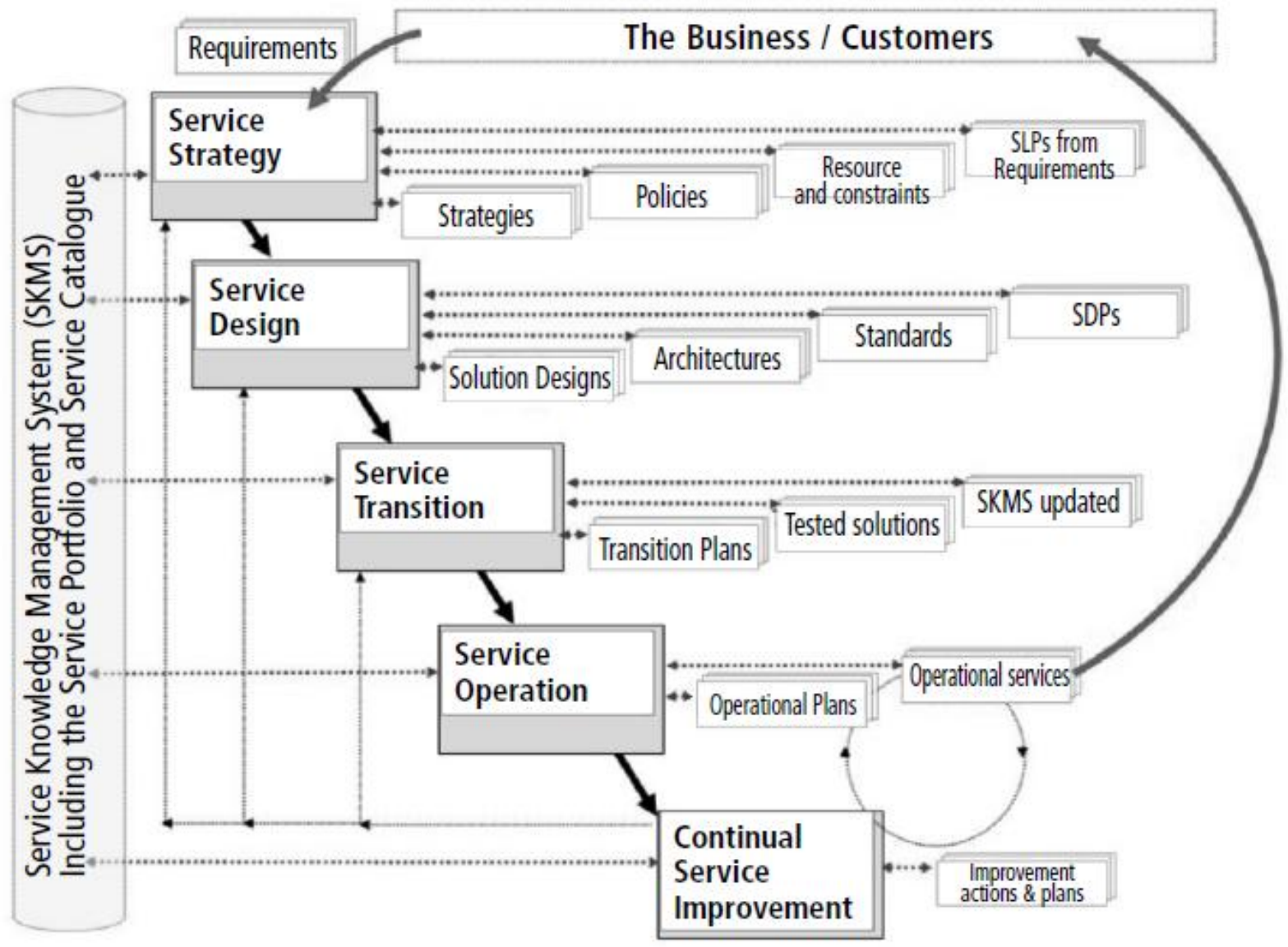

Figure 2. ITIL v3 Service Lifecycle Stages, Inputs, Outputs, and Links (itSMF, 2007)

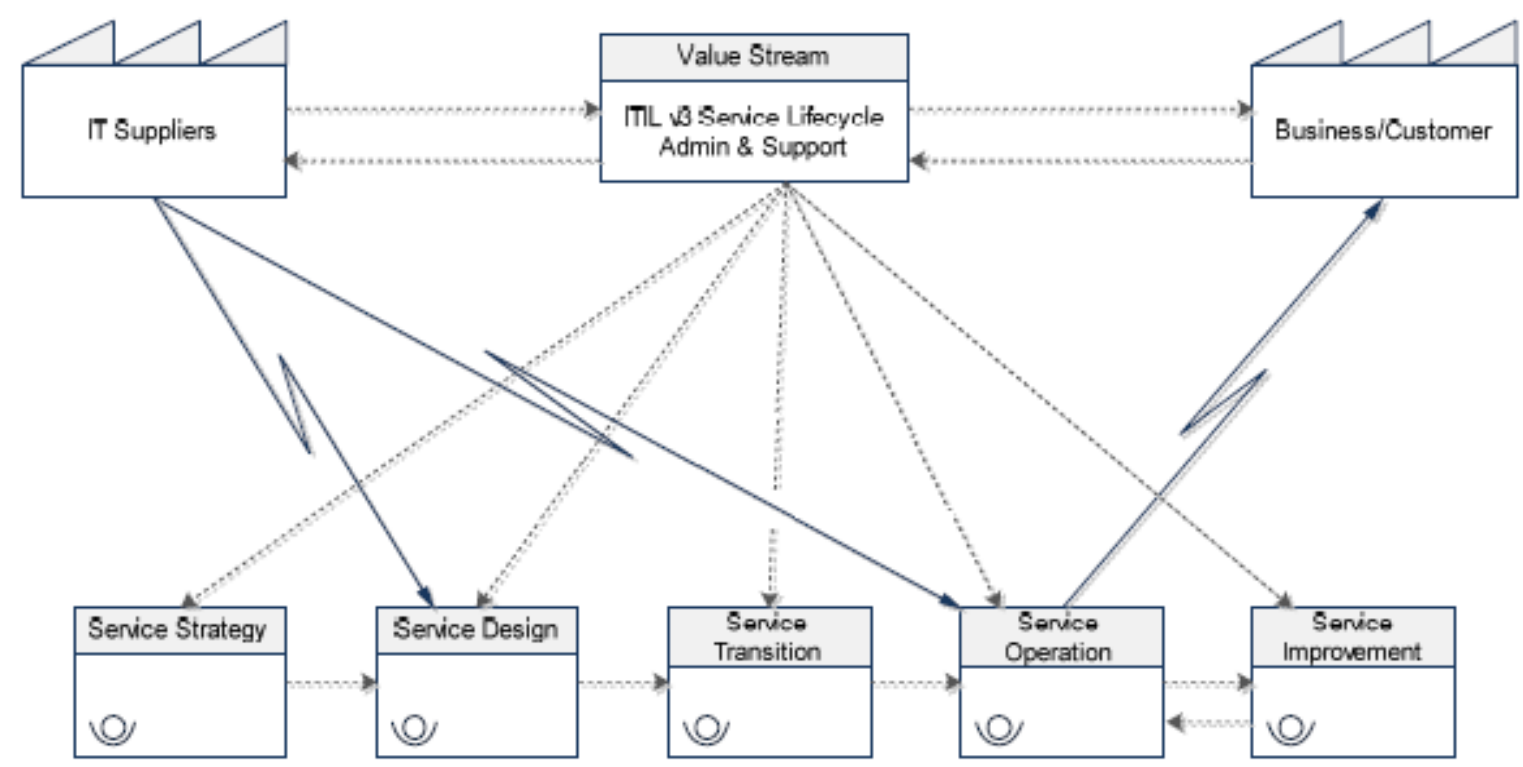

Figure 3. ITIL-Based Value Stream Map for any IT Service 
Although it is only during the service operation stage of the lifecycle that services are actually delivered to the business/customers, ITIL is concerned with more than just delivering services. Each service, process or IT infrastructure component has a lifecycle, and ITIL considers the entire lifecycle from strategy through design and transition to operation and continual improvement as an important staging area to create value added. From a value stream map perspective, the value delivered by any IT service, for example "providing remote access service that enables reliable access to corporate sales systems from sales people's laptops," at the highest level can be mapped as shown in Figure 3.

In the same way that a value stream map can be done at different levels ranging from across companies to multiple plants to a single plant or to a process level, the ITIL-based VSM for an IT service can be mapped at finer levels of granularity because ITIL has defined a key set of processes, activities, and functions required during each stage. For example, Service Operation is comprised of the following five key processes (itSMF, 2007):

$\begin{array}{ll}- & \text { Event Management } \\ - & \text { Incident Management } \\ \text { - } & \text { Request Fulfillment } \\ \text { - } & \text { Access Management } \\ & \text { Problem Management }\end{array}$

In addition, a number of other key activities that are not part of the five processes are also considered as part of Service Operation adding value:

- Monitoring and Control: to detect the status of services and configuration items and take appropriate corrective action,

- Console Management/Operations Bridge: a central coordination point for monitoring and managing services,

- Management of the Infrastructure: storage, databases, middleware, communication, directory services, facilities/data centre, printing, etc., and

- Operational aspects of processes from other lifecycle stages: Change Management, Configuration Management, Release and Deployment Management, Availability Management, Capacity Management, Knowledge Management, Service Continuity Management, etc.

Finally, ITIL recognizes several key functions within the Service Operation stage. They are:
- $\quad$ Service Desk Function
- $\quad$ Technical Management Function
- $\quad$ Application Management Function
- $\quad$ IT Operations Control
- $\quad$ IT Facilities Management

Therefore, an IT service such as monthly payroll processing and associated payments (checks, direct deposits, electronic fund transfers to benefit plan outsourcers and government tax services) along with management reporting and data analysis can be value stream mapped within the context of service operation stage, and then only from the perspective of management of the infrastructure flow of activities. Figure 4 depicts such an example template current-state green stream map. 


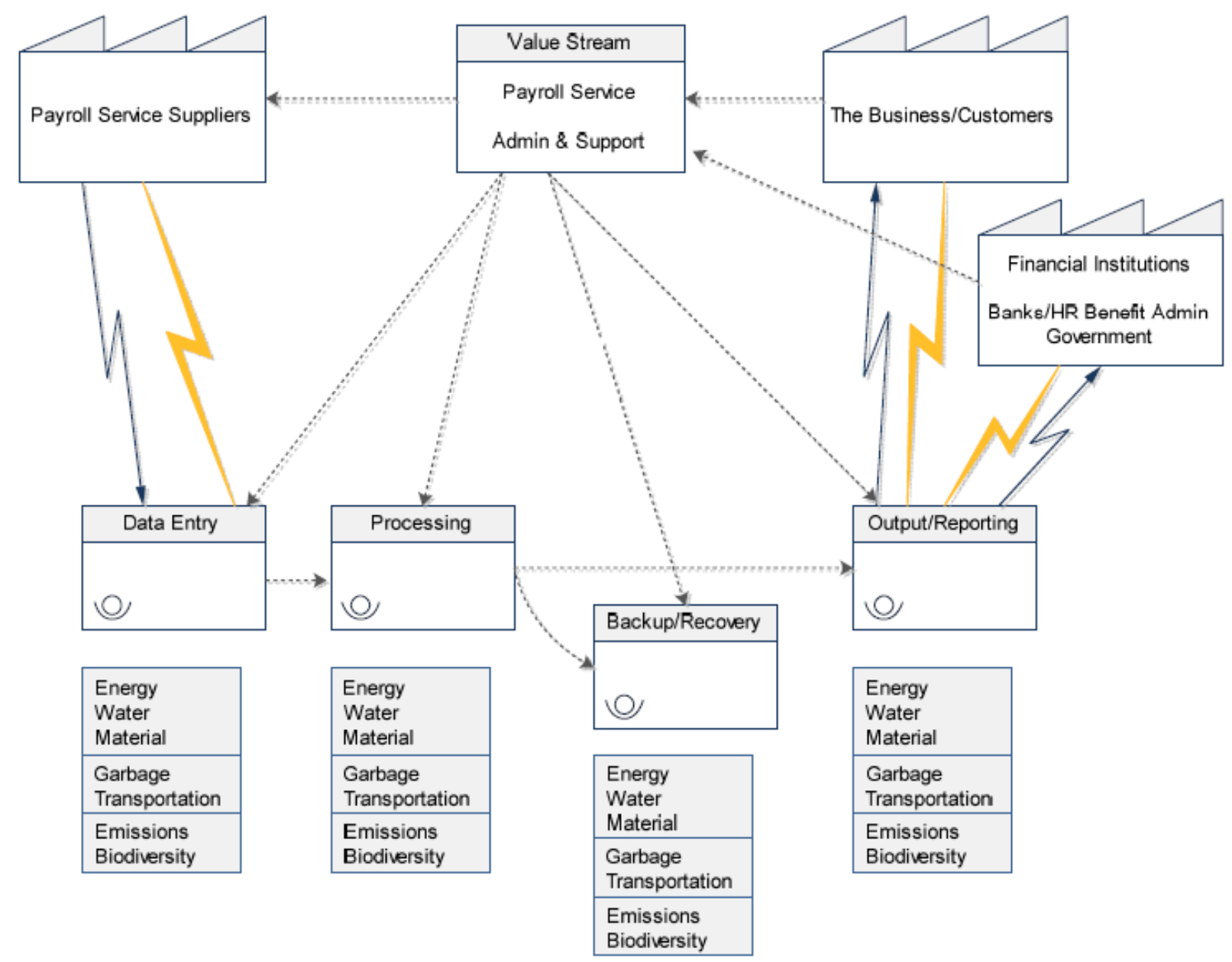

Figure 4. Template Current-State Green Value Stream Map for an IT Service

As another example of IT department's green value stream maps, Figure 5 depicts the operational aspects of Configuration Management sub-processes associated with end-of-life recycling of electronic equipment such as laptops, desktop PC's, CRT monitors, printers, etc.

Once a particular IT value stream has been mapped, the next step involves observing and measuring the seven green wastes (energy, water, material, garbage, transportation, emissions, and biodiversity) in the identified activities on the map and recording the amounts in the data table (box score) under each activity. The resulting current-state green value stream map visually illustrates what and how much of the green wastes are present in that specific IT department value stream. The greening of the IT department begins by prioritizing the value streams to be targeted and devising solutions to minimize their wastes.

Solutions can range from re-thinking computing infrastructure to software performance controls to energywise procurement decisions to changing printing behavior of users. The various feasibility dimensions including economic (cost/benefit), technical, schedule, motivational, and operational, should play a significant role in prioritizing and deciding near-term and long-term projects. Table 2 illustrates some of the current solutions (Herrick and Ritschard, 2009; HP, 2009; Murugesan, 2008) along with their principal impact on each of the seven green waste areas. 


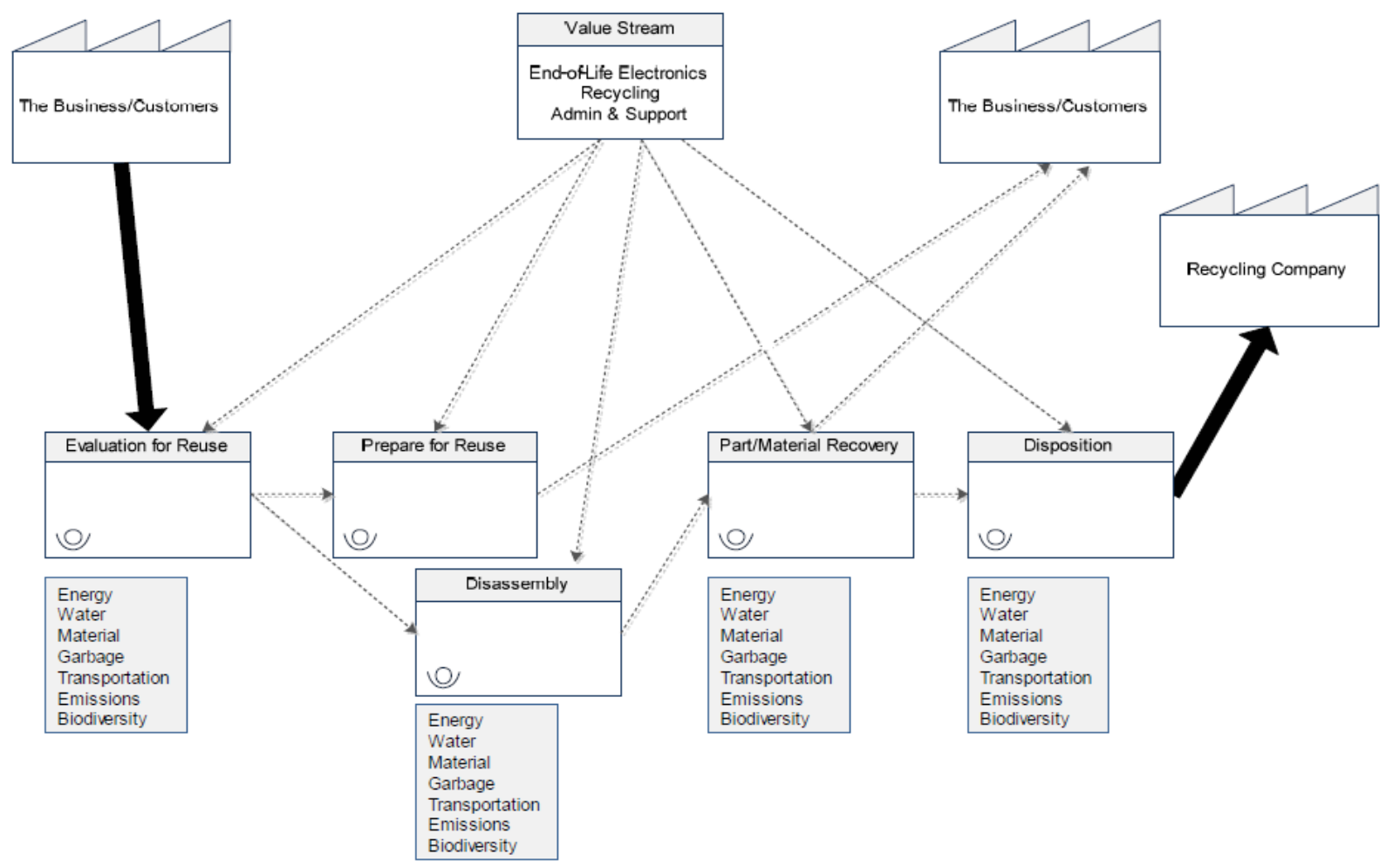

Figure 5. Template Current-State Green Value Stream Map for End-of-Life Recycling Subprocess of ITIL Configuration Management

Table 2. Near-Term and Long-Term Solutions for Green Computing

\begin{tabular}{|c|c|c|c|c|c|c|c|}
\hline & 할 & $\sum_{\bar{d}}^{\bar{d}}$ & 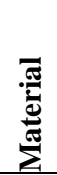 & 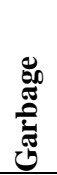 & 岂 & 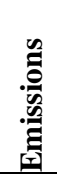 & 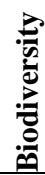 \\
\hline New Server Rooms \& Data Centers Design and Planning & $*$ & $*$ & $*$ & & & $*$ & \\
\hline Renovation of Existing Server Rooms and Data Centers & $*$ & $*$ & $*$ & & & $*$ & \\
\hline Server Virtualization & $*$ & $*$ & & & & $*$ & \\
\hline Desktop (Client) Virtualization & $*$ & & & & & & \\
\hline Thin Clients & $*$ & & & & $*$ & & \\
\hline Cloud Computing & $*$ & $*$ & $*$ & $*$ & $*$ & $*$ & \\
\hline Telecommuting & $*$ & & & & $*$ & $*$ & \\
\hline Teleconferencing & $*$ & & & & $*$ & $*$ & \\
\hline Remote Helpdesk/Management & $*$ & & & & $*$ & $*$ & \\
\hline Energy-Wise Procurement & $*$ & & & & & $*$ & \\
\hline Responsible Disposal and Recycling & & $*$ & & $*$ & & $*$ & $*$ \\
\hline Energy-Wise Retirement/Upgrade of Equipment & $*$ & & & & & $*$ & \\
\hline Hardware Controls for Energy/Power Efficiency & $*$ & & & & & $*$ & \\
\hline Software Controls for Energy/Power Efficiency & $*$ & & & & & $*$ & \\
\hline Wake on LAN Power Management & $*$ & & & & & $*$ & \\
\hline Reducing Printing, Duplex Printing & $*$ & & & $*$ & & $*$ & \\
\hline Flat Panel LCD versus Traditional & $*$ & & & & & $*$ & \\
\hline Laptop versus Desktop & $*$ & & & & & $*$ & \\
\hline Multi-Core Processor versus Single Core & $*$ & & & & & $*$ & \\
\hline Alternative Energy & $*$ & & & & & $*$ & \\
\hline Educate Users, Policies, Regulations, Green Awareness & $*$ & $*$ & $*$ & $*$ & $*$ & $*$ & $*$ \\
\hline
\end{tabular}




\section{CONCLUSION}

A strategy map addressing sustainability in an integral manner has the potential to create a differentiating competitive advantage for an organization. Most IT leaders would agree that they are expected to help improve the organization's sustainability initiatives. Yet, according to a 2008 Forrester Research survey, 55\% do not have an overall plan for green computing (Mines, 2008). On the other hand, ITIL best practices appear to be resonating well with organizations with surveyed adoption rates reported as high as $89 \%$. Therefore, it seems reasonable to integrate planning for sustainability with ITIL best practices. To that end, in this paper, we have introduced the use of Green Value Stream Mapping in conjunction with ITIL best practices' processes as a systematic approach for greening the IT department.

\section{AUTHOR INFORMATION}

Mohammad Dadashzadeh has been affiliated with the University of Detroit (1984-1989), Wichita State University (1989-2003) where he served as the W. Frank Barton Endowed Chair in MIS, and the Applied Technology in Business (ATIB) Program (2003-2009) at Oakland University where he directed more than two million dollars of funded projects at sponsoring organizations. He has authored 4 books and more than 50 articles on information systems and has served as the editor-in-chief of Journal of Database Management. Dr. Dadashzadeh currently serves as Professor of MIS and Chair of the Decision and Information Sciences Department at Oakland University. E-mail: dadashza@oakland.edu. Corresponding author.

T.J. Wharton is Associate Professor of Operations Management at the School of Business Administration, Oakland University in Rochester, Michigan. Dr. Wharton's current research is in manufacturing process improvement, lean manufacturing and sustainability. He has published and presented papers in these areas as well as in statistical process control, flexibility and automation in manufacturing and the use of statistical tools in management education. Dr. Wharton is past chair of the Operations Management Division of the Academy of Management. He has also been active in the Decision Sciences Institute and the Association for Operations Management. E-mail: wharton@oakland.edu.

\section{REFERENCES}

1. Brundtland Report (1987). The report of the Brundtland Commission, also known as: Our common future. Oxford University Press.

2. $\quad$ Esty, D., Daniel C., \& Winston, A. S. (2006). Green to gold. Yale University Press.

3. Herrick, D., \& Ritschard, M. (2009). Greening your computing technology: The near and far perspectives. Proceedings of SIGUCCS'09. Association for Computing Machinery. 297-303.

4. Hewlett-Packard (2009). A green IT action plan for printing and imaging. Hewlett-Packard Development Company.

5. Hird, G. (2008). Green IT in practice: How one company is approaching the greening of its IT. London: IT Governance Publishing.

6. IT Process Maps (2011). Introduction to ITIL® Version 3 and the ITIL $®$ Process Map V3. IT Process Maps GbR.

7. $\quad$ itSMF (2007). An Introductory overview of ITIL $®$ V3. IT Service Management Forum, Ltd.

8. Lazlo, C. (2008). Sustainable value: How the world's leading companies are doing well by doing good. Greenleaf Publishing Ltd. Stanford University Press.

9. $\quad$ Mines, C. (2008). More green progress in enterprise IT. Forrester Research, Inc.

10. Murugesan, S. (2008). Harnessing green IT: Principles and practices. IT Pro. IEEE Computer Society. January/February. 24-33.

11. Nash, M. A., \& Poling, S. R. (2008). Mapping the total value stream: A comprehensive guide for production and transactional processes. New York: NY. Productivity Press.

12. Natural Step (2011). Retrieved on December 5, 2011 from www.naturalstep.org.

13. Orsato, R. J. (2006). Competitive environmental strategies: When does it pay to be green? California Management Review, 48(2). 127-143. 
14. Rother, M., \& Shook, J. (1999.) Learning to see: Value-stream mapping to create value and eliminate muda. Lean Enterprise Institute, Inc.

15. Rusinko, C. A. (2007). Green manufacturing: An evaluation of environmentally sustainable manufacturing practices and their impact on competitive outcomes. IEEE Transactions on Engineering Management, 54(3). 445-454.

16. Wills, B. (2009). Green Intentions. Taylor \& Francis Group Ltd., Productivity Press. New York: NY. 
International Journal of Management \& Information Systems - Second Quarter $2012 \quad$ Volume 16, Number 2

NOTES 